\title{
Cytotoxic Interactive Effects of Dentin Bonding Components on Mouse Fibroblasts
}

\author{
S. Ratanasathien ${ }^{1}$, J.C. Wataha ${ }^{2}$, C.T. Hanks ${ }^{3}$, and J.B. Dennison ${ }^{4}$ \\ ${ }^{1}$ Oral Health Sciences Program, ${ }^{3}$ Department of Oral Medicine, Pathology and Surgery, and ${ }^{4}$ Department of Cariology, Restorative Sciences, and \\ Endodontics, The University of Michigan, School of Dentistry, 1011 N. University Avenue, Ann Arbor, Michigan 48109-1078; ${ }^{2}$ Department of \\ Oral Rehabilitation, Medical College of Georgia, School of Dentistry, Augusta, Georgia 30912-1260
}

\begin{abstract}
Previous studies have shown a wide range of pulpal reactions to dentin bonding systems and a poor correlation between in vitro and in vivo toxicity of dentin bonding agents. Because dentin bonding agents are composed of multiple components which may diffuse through dentin, we hypothesized that these components may cause cytotoxicity through interactive (synergistic) effects. We investigated the cytotoxicities of four dentin bonding components-HEMA, Bis-GMA, TEGDMA, and UDMA-and interactive effects for three binary combinations of the dentin bonding components-HEMA and Bis-GMA, Bis-GMA and TEGDMA, and TEGDMA and UDMA. Cytotoxicities to Balb/c $3 \mathrm{~T} 3$ mouse fibroblasts were measured by the MTT assay. Concentrations which caused $50 \%$ toxicity compared with controls $\left(\mathrm{TC}_{50}\right.$ values) were compared, and the interactive effects were determined by evaluation of the differences between observed and expected MTT activities of the cells. The ranks of toxicity of the dentin bonding components in terms of $\mathrm{TC}_{50}$ values were as follows: Bis-GMA > UDMA > TEGDMA >>> HEMA (least toxic) after 24- and 72-hour exposures. As binary combinations, the three combinations of dentin bonding components interacted in three ways-synergism, additivism, and antagonism-which were influenced by the concentrations of both components. The longer period of exposure resulted in a significant increase in the cytotoxicity of the dentin bonding components and combinations. The findings indicate that both exposure time and the interactions between the dentin bonding components may be important parameters in determining the cytotoxicity of dentin bonding agents in vivo.
\end{abstract}

Key words: bonding (dental), cytotoxicity, fibroblasts.

\section{Introduction}

Dentin bonding agents are primarily used in combination with dental resin composites to reduce microleakage of composite restorations, to provide retention with conservative preparations, and to distribute occlusal stresses (Douglas, 1989). Although clinical and in vivo studies have shown a low incidence of unfavorable effects of dentin bonding systems, pathological changes of pulpal tissues-such as dilatation and congestion of blood vessels, inflammatory responses, and production of irregular dentin as well as odontoblastic displacement-or tooth sensitivity can occur after placement of composite restorations (Stanley et al., 1975; Ostro et al., 1985; Dumsha and Beckerman, 1986; Dogon et al., 1987; Chohayeb et al., 1988; Bowen et al., 1989; Duke et al., 1991; Elbaum et al., 1992). It is possible that dentin bonding agents contribute to these unfavorable pulpal reactions because they are placed directly on dentin. In addition, several lines of evidence suggest that dentin bonding agents may be a possible cause of undesirable pulpal reactions. First, Rathbun et al. (1991) and Hanks et al. (1991) showed that Bis-GMA, which is a major ingredient of most current dentin bonding systems, is easily solubilized from polymerized resins by solvents such as ethanol. Second, an oxygen-inhibited layer prevents complete polymerization of dentin bonding monomers (Rueggeberg and Margeson, 1990). Third, dentin is permeable to a variety of chemicals (Hanks et al., 1994). Therefore, unpolymerized dentin bonding or resin components which remain in the cavities may diffuse to pulp via dentinal fluid (Pashley, 1988; Gerzina and Hume, 1995).

Since current dentin bonding agents have multiple components, interactions among these components may occur when pulpal cells are exposed, resulting in more or less cytotoxicity than the individual components would have caused by themselves. Previous in vitro studies of resin toxicity have not determined the interactions between the components (Dumsha and Sydiskis, 1985; Meryon and Brook, 1989; Hanks et al., 1992). Available studies show that 
pulpal reactions to dentin bonding systems range from none to severe. The severity of pulpal reactions may be influenced by a number of factors, such as composition, clinical application procedure, and dentin permeability (Söderholm, 1991). In the current study, we hypothesized that interactions between components of dentin bonding agents could increase the cytotoxicity of these agents relative to the individual components. The aims of this study were: (1) to assess the cytotoxicity of the dentin bonding components, HEMA, Bis-GMA, TEGDMA, and UDMA, in monolayer cell-cultures; and (2) to determine the interactive effects of toxicity for three binary combinations of dentin bonding components-HEMA and Bis-GMA, Bis-GMA and TEGDMA, and TEGDMA and UDMA--which are primarily present together in dentin bonding systems.

\section{Materials and methods}

The selected dentin bonding components and combinations for toxic assessment are major ingredients in most current dentin bonding systems (Van Meerbeek et al., 1992).

Cultures of Balb/c $3 \mathrm{~T} 3$ mouse fibroblasts, derived from clone A31 (CCL 163, ATCC, Rockville, MD), were used for evaluation of the cytotoxicity of the dentin bonding components. These cells were used because they are contactinhibited and non-tumorigenic and thus have properties similar to those of cells in vivo. In addition, these cells compare favorably with primary cell lines in their cytotoxic response (Wataha et al., 1994). The medium used for culture was Dulbecco's Modified Eagle's Medium (DMEM) with $4500 \mathrm{mg} / \mathrm{L}$ glucose (Gibco, Grand Island, NY), 3\% Nu-Serum (Collaborative Research, Bedford, MA), and supplements (2 $\mathrm{mmol} / \mathrm{L}$ glutamine, 125 units $/ \mathrm{mL}$ penicillin, and $125 \mu \mathrm{g} / \mathrm{mL}$ streptomycin; Gibco, Grand Island, NY).

Balb/c 3T3 cells were plated at 8250 cells per well in $200 \mu \mathrm{L}$ of medium in a 96-well dish (Falcon) and were incubated in 5\% carbon dioxide, $100 \%$ relative humidity, and $37^{\circ} \mathrm{C}$ for $24 \mathrm{~h}$ before dentin bonding components were added. The final cell density was 25,000 cells $/ \mathrm{cm}^{2}$. HEMA (2-hydroxyethyl methacrylate, Batch \#12012DX; Aldrich Chemical Company) was dissolved in sterile distilled water, and Bis-GMA $(2,2-$ bis[(p-2'hydroxy-3'methacryloxy-propoxy)phenyl]propane, Batch \#334-27, Esschem), TEGDMA (triethylene-glycoldimethacrylate, Batch \#334-2, Esschem), and UDMA (urethane dimethacrylate, Batch \#326-28, Esschem) were dissolved in $95 \%$ ethanol. After dilution, the final concentration of $95 \%$ ethanol in the culture medium was $0.5 \%$. One $\mu \mathrm{L}$ of various concentrations of the dentin bonding components was added to each experimental well. The controls for HEMA were $1 \mu \mathrm{L}$ of sterile distilled water, whereas the controls for the other components were $1 \mu \mathrm{L}$ of $95 \%$ ethanol (final concentration $=0.5 \%$ ). Pilot experiments established that $1 \%$ of ethanol caused no cytotoxicity. Eight replicates were used for each concentration. After the cells were exposed to the components for 24 or $72 \mathrm{~h}$, the MTT assay was used for toxicity assessment of the succinic dehydrogenase activity of the cells as well as the number of viable cells, as previously described (Wataha et al., 1992). From the results, the optical densities of treated wells were compared with those of the control wells, and a dose-response curve was plotted to delineate the concentrations of the dentin bonding components which depressed MTT-formazan production by
$50 \%\left(\mathrm{TC}_{50}\right.$ value). We calculated standard deviations and used ANOVA to compare $\mathrm{TC}_{50}$ values for the different dentin bonding components; we used a paired $t$ test to compare $\mathrm{TC}_{50}$ values at 24 and $72 \mathrm{~h}$ for each component.

To assess the toxicity of the binary combinations of dentin bonding components, we plated Balb/c 3T3 cells in 96-well plates and incubated them as previously described. The concentrations of the first component were varied from plate to plate, whereas the concentrations of the second component were varied within each plate. One $\mu \mathrm{L}$ of each component was added to each well; there were 8 replicates per combination. Controls of the HEMA and Bis-GMA combination were $1 \mu \mathrm{L}$ of sterile distilled water and $1 \mu \mathrm{L}$ of $95 \%$ ethanol (final concentration $=0.5 \%$, whereas controls of the BisGMA/TEGDMA and TEGDMA/UDMA combinations were 2 $\mu \mathrm{L}$ of $95 \%$ ethanol (final concentration $=1.0 \%$ ). The plates were incubated for 24 or $72 \mathrm{~h}$ before toxicity assessment. As with single components, the cytotoxicity of the binary combinations was measured by the MTT assay. We determined the interactive effect of the dentin bonding components on the fibroblasts by calculating the difference between the observed toxicity and the expected toxicity. The observed toxicity was obtained from the experiment by analysis of the MTT activity. The expected toxicity of the specific concentrations of the combinations was calculated from the actual optical density (O.D.) of the control samples, as follows:

\section{Expected toxicity $=$ \\ O.D. (Control of Component 1 ) $x$ \\ O.D. (Control of Component 2) \\ O.D. (Control of both Components)}

For example, if a concentration of component 1 caused a $40 \%$ drop in cellular activity, then a $40 \%$ drop was added to all concentrations of component 2. A three-dimensional graph for each combination was produced, with the $X$-and $Y$-axes representing the concentrations of the first and second dentin bonding components, respectively, and the $Z$-axis representing the difference between observed and expected values for the MTT activity. If the observed minus the expected MTT values equalled zero, it represented a simple additive effect (zero interaction). In this case, the toxicity was a simple summation of the individual effects. If the difference between the observed and the expected values was less than zero, it represented a synergistic effect, i.e., the activity of the viable cells in the experiment was less than expected. If the observed minus the expected values was greater than zero, this combination had an antagonistic interaction, in which the observed MTT response was greater than expected. Confidence intervals were calculated for each point on the 3-D surface $(95 \%)$.

\section{Results}

The $\mathrm{TC}_{50}$ values of the dentin bonding components decreased significantly at $72 \mathrm{~h}$ compared with $24 \mathrm{~h}$ (ANOVA and paired $t$ test, $\mathrm{p}<0.001$, Figs. $1 \mathrm{a}, \mathrm{b}$ ). For example, the $\mathrm{TC}_{50}$ value of HEMA dropped from $3600 \mu \mathrm{mol} / \mathrm{L}(\mathrm{SD}=700)$ after $24 \mathrm{~h}$ to $1025 \mu \mathrm{mol} / \mathrm{L}(\mathrm{SD}=30)$ after $72 \mathrm{~h}$. Similar decreases were observed for the other components. The rank of the $\mathrm{TC}_{50}$ values of the 4 dentin components was the same with either time of exposure: Bis-GMA (most toxic) > UDMA > TEGDMA $\gg$ HEMA (least toxic). 
All three types of interactions (synergistic, additive, antagonistic) occurred and were influenced by concentrations of the combinations (Figs. 2a-f). For example, at $24 \mathrm{~h}$, a significant antagonistic effect was found when from 0.5 to $5 \mathrm{\mu mol} / \mathrm{L}$ of Bis-GMA and from 500 to 10,000 $\mu \mathrm{mol} / \mathrm{L}$ of HEMA were present (Figs. $2 \mathrm{a}, \mathrm{b}$ ). Synergism of this combination was prominent when Bis-GMA was present at $25 \mu \mathrm{mol} / \mathrm{L}$ with any concentration of HEMA, but synergism was significant only when from 1000 to 2500 $\mu \mathrm{mol} / \mathrm{L}$ of HEMA were present. At $72 \mathrm{~h}$, there was antagonism at concentrations of $25 \mu \mathrm{mol} / \mathrm{L}$ Bis-GMA and all concentrations of HEMA, $750 \mu \mathrm{mol} / \mathrm{L}$ HEMA, and all concentrations of Bis-GMA, and $2500 \mu \mathrm{mol} / \mathrm{L}$ of HEMA and from 7.5 to $10 \mu \mathrm{mol} / \mathrm{L}$ of Bis-GMA. At 250 to $1,000 \mu \mathrm{mol} / \mathrm{L}$ of HEMA (except $750 \mu \mathrm{mol} / \mathrm{L}$ of HEMA) and 0.5 to 5 $\mu \mathrm{mol} / \mathrm{L}$ of Bis-GMA, significant synergism occurred.

At $24 \mathrm{~h}$, antagonism was more dominant than synergism and additivism for all combinations, whereas at $72 \mathrm{~h}$, the occurrence of antagonism decreased and that of synergism increased considerably, especially in the combination of UDMA and TEGDMA. In addition, the HEMA/Bis-GMA and the Bis-GMA/TEGDMA combinations had similar patterns of toxic interactions at each time interval. For instance, at $24 \mathrm{~h}, 0.5 \mu \mathrm{L}$ of Bis-GMA with any toxic concentration of HEMA or TEGDMA resulted in antagonism, whereas $10 \mu \mathrm{L}$ of Bis-GMA with any toxic concentration of HEMA or TEGDMA resulted in synergism. This phenomenon also occurred at $72 \mathrm{~h}$. However, the third combination, TEGDMA and UDMA, had a different pattern.

\section{Discussion}

There is controversy about the causes of unfavorable pulpal responses under resin composite restorations. A few studies have proposed that bacterial invasion after microleakage results in cellular pathology (Brännström and Nybörg, 1972; Bergenholtz et al., 1982), whereas other reports indicate that chemical toxicity of resins could contribute to pulpal irritation (Vojinovic et al., 1973; Stanley et al., 1975; Franquin and Brouillet, 1988; Qvist et al., 1989; Tagami et al., 1990; Pashley, 1992). The present study demonstrated that, in vitro, synergism and antagonism between components of dentin bonding agents exist. For example, low concentrations of Bis-GMA $(<5 \mu \mathrm{mol} / \mathrm{L})$ antagonized the cytotoxicity of HEMA between 8 and $20 \%$ after 24-hour exposure (Fig. 2a). On the other hand, $25 \mu \mathrm{mol} / \mathrm{L}$ of BisGMA was likely to cause synergism regardless of the concentration of HEMA, and it increased the toxicity $10 \%$ in combination with $1000 \mu \mathrm{mol} / \mathrm{L}$ of HEMA. Other combinations of Bis-GMA and HEMA did not show significant interaction.

The duration of exposure had a strong effect on the toxicity of dentin bonding systems, since the longer period of exposure resulted in a higher incidence of synergistic interactions. For example, the reaction of less than $5 \mu \mathrm{mol} / \mathrm{L}$ of Bis-GMA with HEMA resulted in an 8 to $20 \%$ toxicity reduction (antagonism) after 24-hour exposure (Fig. 2a), but after 72 -hour exposure, the same concentrations increased toxicity $16 \%$ (Fig. 2b). Generally, antagonism was dominant at the 24-hour exposure time, whereas synergism became a dominant interaction at the 72-hour exposure time.
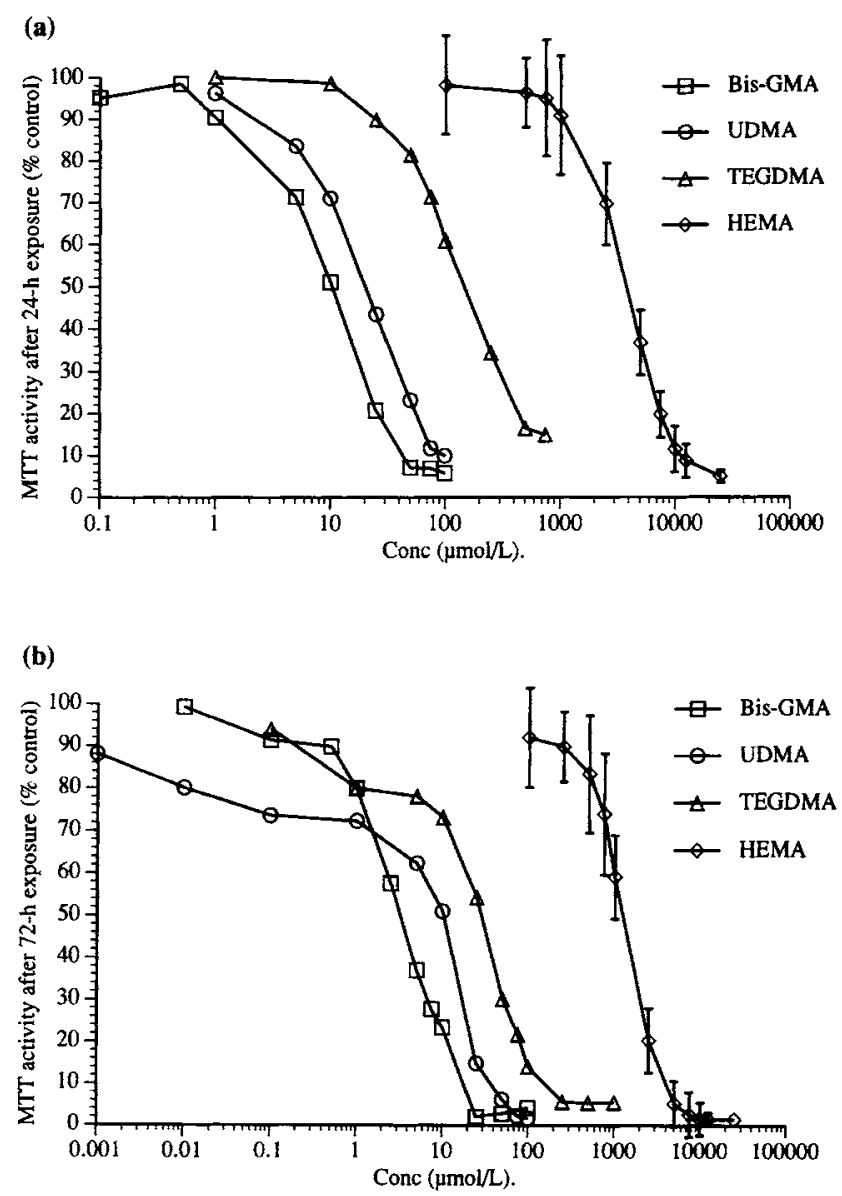

Figure 1. Cytotoxicities of the four dentin bonding components (Exp. 1). Comparison of $\mathrm{TC}_{50}$ values of HEMA, Bis-GMA, TEGDMA, and UDMA at (a) $24 \mathrm{~h}$ and (b) $72 \mathrm{~h}$. At $24 \mathrm{~h}$, the $\mathrm{TC}_{50}$ values were as follows: HEMA - $3600 \mu \mathrm{mol} / \mathrm{L}(\mathrm{SD}=700)$, Bis-GMA - $9.35 \mu \mathrm{mol} / \mathrm{L}(\mathrm{SD}=0.66)$, TEGDMA - $124.5 \mu \mathrm{mol} / \mathrm{L}(\mathrm{SD}=35.2$ ), and UDMA - $17.4 \mu \mathrm{mol} / \mathrm{L}(\mathrm{SD}=6.16)$. At $72 \mathrm{~h}$, the $\mathrm{TC}_{50}$ values were as follows: HEMA - $1025 \mu \mathrm{mol} / \mathrm{L}(\mathrm{SD}=30)$, Bis-GMA - $3.2 \mu \mathrm{mol} / \mathrm{L}$ $(\mathrm{SD}=1.5), \mathrm{TEGDMA}-24.3 \mu \mathrm{mol} / \mathrm{L}(\mathrm{SD}=4.95)$, and UDMA - 10.01 $\mu \mathrm{mol} / \mathrm{L}(\mathrm{SD}=0.03)$. Error bars (standard deviations) of each component were determined, but error bars are shown only for HEMA to reduce clutter.

Furthermore, it was observed that interactions often occurred at concentrations below those necessary for individual resins to be toxic. Therefore, when one is assessing the cytotoxic potential of a resin which releases multiple components, knowing the individual cytotoxicities of the components is not adequate. From the current study, it was clear that synergism and antagonism could exist in the same system. This may mean that multiple mechanisms are involved in the cytotoxicity of these resins-each mechanism acting at specific concentrations and time conditions. Additional evidence would be necessary to support this hypothesis.

The existence of synergistic interactions means that dentin bonding agents have the potential to cause toxic responses in pulp at lower levels than they could by themselves. Since resins are known to release concentrations which may cause these reactions, the interactions have in vivo relevance. For example, HEMA and TEGDMA release 

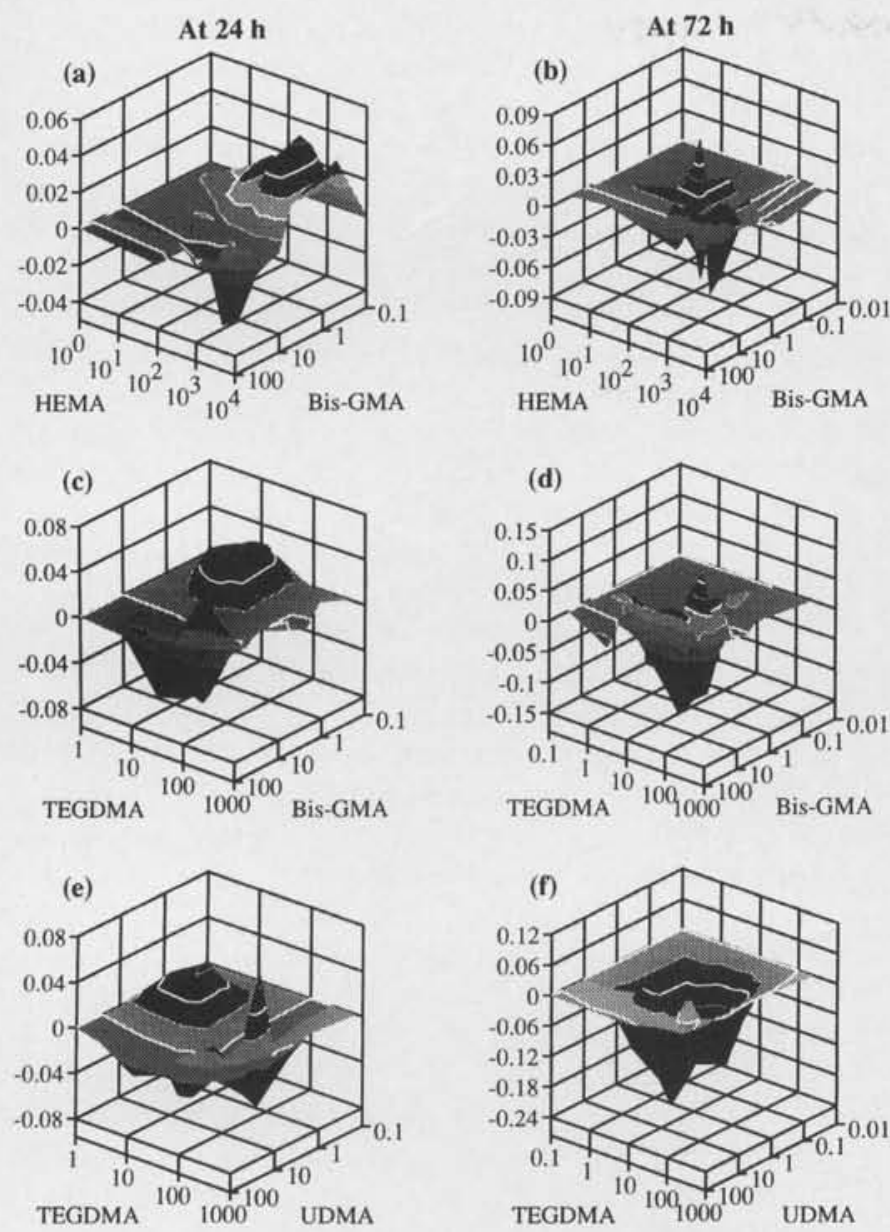

Figure 2. Interactive effects of binary combinations of dentin bonding components (Exp. 2). (a) HEMA and Bis-GMA at $24 \mathrm{~h}$. (b) HEMA and Bis-GMA at $72 \mathrm{~h}$. (c) Bis-GMA and TEGDMA at $24 \mathrm{~h}$. (d) Bis-GMA and TEGDMA at $72 \mathrm{~h}$. (e) TEGDMA and UDMA at 24 h. (f) TEGDMA and UDMA at $72 \mathrm{~h}$. The $X$ - and $Y$-axes represent the concentrations of the components in $\mu \mathrm{mol} / \mathrm{L}$, and the $\mathrm{Z}$-axis represents the observed-expected MTT activity. Blackened areas of the 3-D surfaces indicate areas of effect significantly different from zero. $95 \%$ confidence intervals were $0.03,0.03,0.02,0.05,0.02$, and 0.03 , for (a) through (f), respectively.

at approximately $30 \pm 13$ and $172 \pm 95 \mathrm{nmol}$, respectively, in three days (Gerzina and Hume, 1994). Rueggeberg et al. (1995) showed that in a copolymer of TEDGMA and BisGMA, Bis-GMA was the major component, and leaching was in the range of 10 to $30 \%$ of its original abundance.

The validity of the MTT assay was confirmed by comparison of the cytotoxicities of the individual components with those of previous experiments (Hanks et al., 1991), which showed similar cytotoxicity results for these resins (Bis-GMA, TEGDMA, and UDMA). Cytotoxicity of HEMA in the current study was in agreement with that in another study (Bouillaguet et al., 1995), but not with that in the study done by Hanks et al. (1992). Therefore, we verified our results by repeating the HEMA experiment several times.

Our model to determine interactions has been commonly used in pharmacology and toxicology (Magos, 1981; Prichard and Shipman, 1990). However, experimental variation was a critical factor in statistical demonstration of these interactions. Since we determined interactions by computing the observed minus expected cytotoxicities, the error of this difference was a combination of the errors for observed and expected values. We were able to minimize these errors by using eight replicates for each concentration and using the MTT assay, which provided minimal variation. We further validated our results by repeating experiments to verify the shapes of the three-dimensional surfaces.

The present study has shown that the different resins which are present in dentin bonding agents can interact to alter cytotoxicity in vitro. These interactions may cause the resins to be more or less toxic than the sum of the individual toxicities, but prolonged duration of exposure was likely to increase toxicity of the resins. The mechanisms of these interactions remain unknown. Since the interactions occurred at concentrations which have been shown to be released from resins in vitro, they may be relevant to pulpal irritation in vivo. However, further studies which quantify the concentrations released, the concentrations which diffuse through dentin, and the duration of such leaching are necessary for understanding of the role of these interactions in pulpal irritation.

\section{Acknowledgments}

This investigation was supported in part by USPHS Research Grant DE 09296 from the National Institute of Dental Research, National Institutes of Health, Bethesda, MD 20892.

This paper is based on a thesis submitted to the graduate faculty, University of Michigan School of Dentistry, in partial fulfillment of the requirements for the Master of Science in Restorative Dentistry.

\section{References}

Bergenholtz G, Cox CF, Loesche WJ, Syed SA (1982). Bacterial leakage around dental restorations: its effect on the dental pulp. J Oral Pathol 11:439-450.

Bouillaguet S, Wataha JC, Hanks TC, Ciucchi B, Holz J (1995). In vitro cytotoxicity and dentin permeability of HEMA (2hydroxyethyl methacrylate). J Endo (in press).

Bowen RL, Rupp NW, Eichmiller FC, Stanley HR (1989). Clinical biocompatibility of an experimental dentineenamel adhesive for composites. Int Dent J 39:247-252.

Brännström M, Nybörg H (1972). Pulp reaction to composite resin restorations. J Prosthet Dent 27:181-189.

Chohayeb AA, Bowen RL, Adrian J (1988). Pulpal response to a dentin and enamel bonding system. Dent Mater 4:144-146.

Douglas WH (1989). Clinical status of dentine bonding agents. J Dent 17:209-215.

Dogon IL, Van Leeuwen MJ, Heeley JD (1987). A comparison of the pulpal response to two dentin bonding agents (abstract). J Dent Res 66:772.

Duke ES, Robbins JW, Snyder DS (1991). Clinical evaluation of a dentinal adhesive system: three-year results. Quintessence Int 22:889-895.

Dumsha TC, Beckerman T (1986). Pulp response to a dentin bonding system in miniature swine. Dent Mater 2:156-158.

Dumsha TC, Sydiskis RJ (1985). Cytotoxicity testing of a dentin 
bonding system. Oral Surg Oral Med Oral Pathol 59:637-641.

Elbaum R, Remusat M, Brouillet JL (1992). Biocompatibility of an enamel-dentin adhesive. Quintessence Int 23:773-782.

Franquin JC, Brouillet JL (1988). Biocompatibility of an enamel and dentin adhesive under different conditions of application. Quintessence Int 19:813-826.

Gerzina TM, Hume WR (1994). Effect of hydrostatic pressure on the release of monomers through dentin in vitro (abstract). J Dent Res 73:224.

Gerzina TM, Hume WR (1995). Effect of hydrostatic pressure on the diffusion of monomers through dentin in vitro. J Dent Res 74:369-373.

Hanks CT, Strawn SE, Wataha JC, Craig RG (1991). Cytotoxic effects of resin components on cultured mammalian fibroblasts. J Dent Res 70:1450-1455.

Hanks CT, Wataha JC, Parsell RR, Strawn SE (1992). Delineation of cytotoxic concentrations of two dentin bonding agents in vitro. J Endod 18:589-596.

Hanks CT, Wataha JC, Parsell RR, Strawn SE, Fat JC (1994). Permeability of biological and synthetic molecules through dentin. J Oral Rehabil 21:475-487.

Magos L (1981). Synergism and antagonism in metal toxicology. In: Systemic aspects of biocompatibility. Vol. 1. Williams DF, editor. Boca Raton, FL: CRC Press, pp. 87-100.

Meryon SD, Brook AM (1989). In vitro cytotoxicity of three dentine bonding agents. J Dent 17:279-283.

Ostro E, Keall CL, Keall HJ, Cox CF (1985). Pulpal response in monkey teeth with controlled smear layer removal (abstract). J Dent Res 64:222.

Pashley DH (1988). Consideration of dentine permeability in cytotoxicity testing. Int Endod J 21:143-154.

Pashley DH (1992). The effects of acid etching on the pulpodentin complex. Oper Dent 17:229-242.

Prichard MN, Shipman C (1990). A three-dimensional model to analyze drug-drug interactions. Antiviral Res 14:181-206.
Qvist V, Stoltze K, Qvist J (1989). Human pulp reactions to resin restorations performed with different acid-etch restorative procedures. Acta Odontol Scand 47:253-263.

Rathbun MA, Craig RG, Hanks CT, Filisko FE (1991). Cytotoxicity of a Bis-GMA dental composite before and after leaching in organic solvents. J Biomed Mater Res 25:443-457.

Rueggeberg FA, Margeson DH (1990). The effect of oxygen inhibition on an unfilled/filled composite system. J Dent Res 69:1652-1658.

Rueggeberg FA, Tamareselvy K, Ergle JW (1995). Network conversion and leachability of Bis-GMA/TEGDMA copolymers (abstract). J Dent Res 74:183.

Söderholm KJ (1991). Correlation of in vivo and in vitro performance of adhesive restorative materials: a report of the ASC MD 156 Task Group on test methods for the adhesion of restorative materials. Dent Mater 7:74-83.

Stanley HR, Going RE, Chauncey HH (1975). Human pulp response to acid pretreatment of dentin and to composite restoration. J Am Dent Assoc 91:817-825.

Tagami J, Sugizaki J, Hosada H (1990). Effect of various pretreatments for dentin bonding on dentin permeability (abstract). Shika Zairyo Kikai 9:240-246.

Van Meerbeek B, Inokoshi S, Braem M, Lambrechts P, Vanherle $G$ (1992). Morphological aspects of the resin-dentin interdiffusion zone with different dentin adhesive systems. J Dent Res 71:1530-1540.

Vojinovic $\mathrm{O}$, Nybörg H, Brännström M (1973). Acid treatment of cavities under resin fillings; bacterial growth in dentinal tubules and pulpal reactions. J Dent Res 52:1189-1193.

Wataha JC, Hanks CT, Craig RG (1992). In vitro synergistic, antagonistic, and duration of exposure effects of metal cations on eukaryotic cells. J Biomed Mater Res 26:1297-1309.

Wataha JC, Hanks CT, Sun Z (1994). Effect of cell line on in vitro metal ion cytotoxicity. Dent Mater 10:156-161. 